\title{
ACTUALIDAD TERRITORIAL DE LAS MONTAÑAS. DISTINTAS MIRADAS, NUEVAS POLÍTICAS
}

\author{
Josefina Gómez Mendoza \\ Universidad Autónoma de Madrid
}

\section{RESUMEN}

La Comisión especial del Senado de España para el estudio sobre las medidas a desarrollar para evitar la despoblación de las montañas ha concluido sus trabajos tras escuchar a cincuenta comparecientes entre expertos, políticos, entre ellos alcaldes de municipios de montaña, y organizaciones sociales. Destaca de su informe final la apuesta por una estrategia territorial e integrada, las políticas activas, la desvinculación de las ayudas con carácter exclusivo a la agricultura de montaña, y finalmente las medidas propuestas para favorecer retornos: identificación de macizos, medidas fiscales, dotación de servicios y equipamientos básicos, movilidad y conectividad con banda ancha. En el texto se repasa la evolución demográficos comparada con Europa, se comparan las miradas del ingeniero-escritor y del escritor nacido en un pueblo inundado, y se discuten las propuesta. Se concluye que la montaña no debe se considerada problema sino fuente de nuevas oportunidades.

\section{ABSTRACT \\ Territorial present of mountains. Different views, new politics}

The Spanish Senate created a Work Group on the measures to be developed to prevent the depopulation of the mountains, which has completed its work after listening to fifty persons between experts, politicians, including mayors of municipalities of mountain, ONGs. Its final report includes: a territorial and integrated strategy, active policies, to aid other activities different that mountain agriculture as until now, and finally the measures proposed to promote returns to mountain areas: tax measures, provision of services and basic equipment, good mobility and good internet connectivity. The paper discusses comparative demographic evolution of European and Iberian mountains, different views of an engineer-writer and a writer born in a flooded village; and different points of view 
about causes of depopulation, y measures to be taken. Mountain must be considered as an opportunity better than a problem.

Key words: mountain, depopulation, literature, Senate, equipment, compensation measures

Desde los ya lejanos tiempos en que se fraguó nuestra amistad cuando él estudiaba el Campo de Cartagena y yo el corredor del Henares, siempre he admirado de Alfredo Morales Gil su inteligente conocimiento del territorio y su capacidad para esclarecer los procesos y los cambios que se han producido en el uso de los recursos, en particular los hídricos en el SE de la Península Ibérica. Es sin duda el gran geógrafo de la cuenca del Segura, pero es también el que mejor ha entendido la gestión de recursos escasos como agua y suelo en medio semiárido, el papel de las aguas de turbias en los piedemontes del SE, las transformaciones de los regadíos y la impresionante competencia por el agua de los usos turísticos. Recuerdo con entusiasmo la explicación que nos regaló en un recorrido por «su terreno» con motivo de un coloquio de mediados de los años noventa del siglo pasado, enseñándonos los sistema de riegos tradicionales, y también nuevas formas de acumulación de agua en embalses o bolsas. Pero quiero sobre todo presumir de la amistad que nos une, por su excelente carácter, su buen criterio, su delicadeza y habilidad para gestionar situaciones complejas. Los párrafos siguientes quieren ser un modesto pero sincero y afectuoso homenaje a su figura, como geógrafo y como persona.

Desde octubre 2014 y hasta julio 2015, fecha en que emitió su informe final, ha llevado a cabo sus trabajos en el Senado la llamada Comisión especial de estudio sobre las medidas a desarrollar para evitar las despoblación de las zonas de montaña. Había sido creada, más de un año antes, a instancias en primer lugar del Senador Francesc Boya del grupo Entesa, antiguo síndico de Arán, y presidente de la recientemente creada Asociación española de Municipios de montaña (EsMontaña). El Senador argumentó criterios de equidad territorial $\mathrm{y}$, en concreto, de dotación de servicios en áreas geográficamente marginales. Los Grupos del Senado coincidieron en que sobre la cuestión había que evitar en lo posible la confrontación política y tratar en cambio de sumar opiniones e iniciativas para lograr un país que no consienta los vacíos de población, desaproveche recursos y abandone patrimonios. También coincidieron en que no se quería tanto plantear políticas de subsidios como ayudar a movilizar recursos y lograr actividades sostenibles en las nuevas condiciones de dificultad y de marginalidad de las zonas de montaña. El 26 de junio 2015, tras escuchar a 50 
comparecientes, la Comisión emitió su informe que fue aprobado por el Pleno sin ninguna rectificación (Senado, Informe, 2015)

Comparecieron [comparecimos] sobre todo alcaldes de municipios de montaña (cántabros y leoneses, del Pirineo y de la montaña Ibérica, de la sierra Morena, de los montes de Málaga...), representantes de asociaciones europeas de montaña, políticos autonómicos, expertos académicos (de diez, la mitad geógrafos), miembros de ONG, empresarios. Todas las intervenciones están publicadas en la página web del Senado (Publicaciones, 2015): resultan particularmente interesantes los testimonios de los alcaldes que, por la cercanía y protagonismo en los problemas, aportan información insustituible y muestran bien que las zonas de montaña, aunque tengan rasgos comunes como por ejemplo marginalidad y vulnerabilidad, no dejan de ser todas y cada una singulares, y este es quizá el punto fundamental que deben retener, a mi juicio, políticos y técnicos. La montaña quizá sea en primer lugar tiranía, si no de la geografía, sí de la orografía. Pero hay algo aún más evidente: en los sistemas orográficos ibéricos a veces no importa tanto la altitud como el clima, de modo que las meridionales son realmente montañas muy distintas. Por otra parte, más de un compareciente señaló hasta qué punto los problemas y las medidas no se pueden concebir solo «desde fuera»: como expresivamente dijo Valentín Cabero Diéguez, catedrático emérito de geografía de Salamanca: los que más autoridad tienen para exponer sus problemas son tanto un pastor trashumante que aún desciende desde el valle del Prioro hasta Extremadura, como las mujeres campesinas que en los valles olvidados de la Sierra de Caurel, de Sanabria, de Ancares, de los Pirineos mantienen vivos los cultivos de sus huertos o los soutos de castaños. El lema del primer congreso de EsMontañas, celebrado en Somiedo en diciembre 2014, organizado por Reader, la red asturiana para el desarrollo rural decía precisamente: «Construyendo una propuesta por, para y desde la montaña».

\section{Ciclos DEMOGRÁFicos COMPARADOS}

Valentín Cabero resumió bien lo ocurrido en las montañas como dicotomía entre, por un lado, los decenios 1950-1970 y, por otro, los veinte últimos años del siglo pasado: primeros «olvidadas», herencia de la etapa de la autarquía; luego «conquistadas», a partir de los embalses de la minería, del turismo; «despobladas», procediendo de nuestras montañas periféricas cerca de la mitad de los siete millones de españoles que salen del medio rural entre 1955 y 1975; y, por último, en el momento actual, estaríamos en la fase de «las montañas preservadas» que algunos intentan reconquistar con una vuelta a modelos productivos inteligentes y manteniendo relaciones de equilibrio con los territorios urbanos. Eduardo Martínez de Pisón, como buen naturalista, lo expresó en estos términos: «la montaña es un buen paisaje pero un mal territorio». Valoración en la 
que está de alguna forma contenido el contraste entre los sobresalientes valores y recursos naturales y culturales y la dificultad para vivir territorios inhóspitos por su altitud, su clima, y su potencialidad agrícola reducida. Pero una vez más, hay montañas y montañas.

Fernando Collantes, historiador de la economía, uno de los mejores conocedores de la historia demográfica comparada de las montañas, señala que se ha producido un relativo vacío en la historiografía de la población del mundo rural español en el siglo xx, ya que los historiadores (y los economistas, como José Manuel Naredo en su tan conocido libro de 1971) habrían prestado más atención a la evolución de la agricultura que a la de las comunidades rurales. Según él, son los geógrafos los que más se han ocupado de los cambios en la población rural. En todo caso, es el propio Collantes el que mejor ha contribuido a llenar este vacío, en términos de historia demográfica comparada. En el libro escrito junto con Vicente Pinilla, expresivamente llamado Peaceful Surrender. The depopulation of Rural Spain (2011) [que con su título quiere en cierta forma ser réplica del de Sidney Pollard, Peaceful Conquest. The Industrialisation of Europe 1760-1960] suministran una imagen completa y comparada de la evolución de la población rural española, caracterizada por el retraso en el desencadenamiento de la emigración del campo a la ciudad y luego, en cambio, por su aceleración y su mayor intensidad, fenómenos que explica por el retraso urbano e industrial. En el espacio de una generación la población rural cayó cerca de un $25 \%$. Tras The long siesta, como calificó un historiador inglés el lento crecimiento de la agricultura española (Simpson, 1995), se habría producido la rendición pacífica del mundo rural, replican Collantes y Pinilla.

La evolución demográfica de la población de las montañas sigue el patrón general pero resultan particularmente interesantes sus variaciones regionales. También es Collantes quien lo ha estudiado desde la perspectiva comparada. El éxodo en las zonas de montaña tuvo un arranque tardío en España, demorándose casi medio siglo en relación con Francia o el Reino Unido, hasta los decenios de 1950 y 1960. Eso sí, a partir de entonces, el proceso ha sido mucho más intenso, extenso y prolongado. Mientras que las Altas Tierras Escocesas y los Pirineos habían perdido población desde mediados del siglo XIX, pero habían logrado estabilizarla después de la segunda guerra mundial, en las montañas españolas del norte y del interior, las pérdidas empezaban realmente en aquellos años. España se habría comportado con respecto a los países de más rápida industrialización y urbanización como lo están haciendo ahora, con respecto a nosotros, los del Este europeo (todavía hay altas densidades de población rural en Rumanía o Bulgaria) o los de la cuenca sur del Mediterráneo (Collantes, 2004 y 2005)

Una de las conclusiones más interesantes de estos trabajos radica en que hace manifiestas las diferencias entre sistemas montañosos regionales. Los más 
afectados son los del Noroeste y centrales, mientras que el Pirineo siempre se ha comportado mejor; y en las montañas del Sur se inició más tarde el éxodo, de modo que en los años cincuenta mantenían todavía algún crecimiento pero, en cambio, sus pérdidas se están prolongando más tiempo. En conjunto, el historiador aragonés concluye que la falta de accesos, la falta de servicios y de equipamientos, así como la ausencia de una cabecera comarcal han incrementado la gravedad de los problemas demográficos. Despoblación que ha ido unida a la pérdida de las actividades rurales: si al principio del proceso solo un $18 \%$ de la población de los municipios de montaña no se dedicaba a la agricultura, ahora no lo hace más del $80 \%$. Y despoblación que tiene los corolarios inevitables de enorme envejecimiento, desvitalización, consanguineidad y aumento de la tasa de masculinidad, porque son las mujeres las que menos oportunidades de empleo encuentran en las zonas montañosas. Fernando Molinero ha cartografiado hasta qué punto la desvitalización afectaba a los municipios de montaña: «La situación de rural profundo [...] está especialmente concentrada en las montañas y en las llanuras cerealistas de secano. Las cordilleras ibérica y cantábrica, las llanuras del Duero, así como las castellano-manchegas y extremeñas, reflejan nítidamente este proceso de pérdida de habitantes, de empleos, de servicios y de dinamismo económico que tampoco se puede detener explotando sus ventajas comparativas: el paisaje, el patrimonio, y su carácter rural persistente en el tiempo y en el espacio.» (Molinero, 204: 106; Sánchez Aguilera y García Coll, 2004: 90 y 105).

Los comparecientes ante la Comisión del Senado han puesto de manifiesto de forma muy elocuente los desequilibrios de las pirámides de población local. «Hay treinta osos y no hay treinta niños. Hay más osos que niños» subrayó J.M. González, Peridis refiriéndose a La Pernía, en la montaña palentina. Y el alcalde de Yunquera de Málaga proyectó la pirámide de población de su pueblo, sin primer escalón porque no hay ningún niño menor de cinco años. Son pueblos, los de montaña, que en su mayoría han quedado en el limbo, como se dijo en el Senado.

Algunas circunstancias apuntan, sin embargo, a un cambio de tendencia en los últimos años (Guirado y Cuadrado, 2009). Para empezar, y con carácter general, el cambio censal que se ha producido en 2001 ha suprimido, como es sabido, el concepto de transeúnte y, por tanto, de población de hecho, y los ha sustituido por el nuevo concepto de población vinculada (censables que tienen algún tipo de vinculación con el municipio y en el que suelen residir algún tiempo) para estimar mejor la carga real de población que soporta cada municipio. Disponer de la información de la población vinculada permite, sin duda, localizar mejor, afinar el análisis geodemográfico, en la medida en que se está hablando del territorio habitado. La función residencial de carácter estacional que cumplen algunos municipios de montaña les ha conferido cierto dinamismo, 
pero sin olvidar que es discontinuo. Se trata en su mayor parte de población vinculada no residente fija, que no siempre contribuye a mantener el territorio. Cabero habló de más de un millón de personas vinculadas no residentes en Castilla y León y sostuvo que deberían tener más compromiso con sus lugares. En general, los elementos de dinamización demográfica se suelen concentrar en las cabeceras comarcales, y allí donde no existen, el panorama no ha mejorado. Lo que aboga a favor de las comarcas y de la comarcalización que, como es sabido, es cuestión recurrente y controvertida.

\section{Generaciones de estudios geográficos sobre las montañas. Algunos HITOS}

Contamos con buenos trabajos geográficos sobre este ciclo largo de abandono de las montañas. Fue una cuestión que dio sentido y orientación a los estudios de carácter regional de los años sesenta y setenta del siglo pasado. La primera tesis regional había sido precisamente el estudio de Salvador Llobet Reverter sobre el Montseny, pero es José Ortega Valcárcel en su libro sobre las Montañas de Burgos, espacio regional que coincide más o menos con el antiguo partido de Villarcayo, quien advirtió de que los cambios que se estaban produciendo en el poblamiento y la organización tradicional eran consecuencia del influjo de la aglomeración de Bilbao. «Entre lo antiguo y lo moderno, las Montañas de Burgos se nos muestran en un momento de cambio de piel» (Ortega, 1974: 11). Poco después, Valentín Cabero ponía de manifiesto cómo en La Cabrera desde los años 60 el proceso de emigración hacia Europa, las zonas industriales y Ponferrada estaba dando lugar a la crisis de la economía campesina y la regresión del espacio cultivado, iniciándose una degradación de la calidad paisajística que el policultivo tradicional de subsistencia había mantenido tantos siglos (Cabero, 1980: 107-112). Por su parte, Francisco Rodríguez estudiaba los procesos de la Serranía de Ronda (Rodríguez, 1977); y por fin, respecto de un cambio de ciclo montañés en un medio muy singular, Manuel Valenzuela publicaba su tesis sobre Urbanización y crisis rural en la Sierra de Madrid (Valenzuela, 1977).

El estudio pionero de Georges Bertrand sobre la biogeografía de la Liébana (1964) inició un largo itinerario de trabajos suyos del que uno de los hitos fue la publicación diez años después de su tesis sobre la cordillera Cantábrica Central (1974), a la que siguieron estudios particularmente perspicaces consagrados entre otras cosas al declive de la economía agropastoril. Recientemente se ha rendido justo homenaje en la Universidad de Santander a la trayectoria del geógrafo de Toulouse (Bertrand, 2014). Lo que me importa subrayar es que la metodología geosistémica empleada tuvo amplia repercusión entre los geomorfólogos estructuralistas y los geógrafos agraristas españoles que la adaptaron a 
través del concepto de agrosistema. Suponía una nueva visión integrada de la geografía física, donde la biogeografía ganaba en protagonismo, pero en la que también los usos (y desusos) del suelo eran analizados para seguir la evolución de los paisajes. En los setenta años de transformación de la Liébana, en que ha perdido la mitad de su población (a pesar de ser un destino turístico consolidado), son las pequeñas aldeas emplazadas a mayores alturas las principales perdedoras: un centenar de aldeas que, con sus habitantes, ganados y vías de comunicación habían sido hasta aquel momento las grandes artífices del paisaje: se ha empobrecido el mosaico de usos del suelo, la cubierta forestal y de matorral se ha ido adueñando rápidamente de parte del territorio $\mathrm{y}$, la trashumancia ha desaparecido, instalándose en cambio animales traídos de todas las partes del mundo (García Codrón, en Bertrand, 2014: 19).

Al referirse a su trayectoria, Bertrand la concibe como el paso de un proyecto geomorfológico «metodológicamente balizado», inspirado por Taillefer, a una especie de aventura paisajística, en el que el propio terreno habría sido instigador e incluso portador del proyecto (Bertrand, 2014: 35 y 39-43). De la Liébana individualizada e identificada como cuenca intramontana con caracteres mediterráneos en plena montaña húmeda y nebulosa, evolucionó hacia un modelo que integra no solo la acción antrópica, sino incluso las representaciones culturales y paisajísticas de la montaña. Con todo, los trabajos españoles más o menos atentos al concepto de paisaje integrado de Bertrand se atuvieron en los años ochenta, tanto los de la Cordillera Central, como los de la Cantábrica, o los Montes de Toledo, a la geomorfología, aun con planteamientos de sistema natural. Este grupo de geógrafos, bajo la dirección de Eduardo Martínez de Pisón, han introducido después en sus estudios el sentido paisajístico, la delimitación de unidades de paisaje y de áreas de protección, particularmente en aras a la declaración de parques nacionales (Martínez de Pisón, 2008 y 2013; Sanz y Martínez de Pisón, 2015). Por su parte, los estudios aragoneses y navarros de los años setenta fueron, o bien sobre todo de geomorfología dinámica (Ibáñez Marcellán, 1974), o, en el caso de la geografía regional y humana, de planificación territorial (Calvo Palacios, 1977)

Otro grupo diferente es el del Instituto de Estudios Pirenaicos de Jaca, encabezado por José María García Ruiz y el ecólogo Enrique Balcells Rocamora que a partir de estudios de los modos de vida tradicionales basados en la explotación, para la subsistencia, de todos los recursos próximos (García Ruiz, 1976) han desembocado en estudios de geoecología (García Ruiz, 1996), y más directamente de ecología del paisaje (Lasanta, 2014). Los principales trabajos han sido consagrados a la pérdida de la agricultura de montaña (Lasanta, 1989), los efectos sobre la erosión desencadenados por el abandono de campos (Ruiz Elcano, 1993) o los efectos geomorfológicos de las repoblaciones forestales (Ortigosa, 1991). En su libro más reciente sobre la Sierra de Cameros, Teodoro 
Lasanta, mide, con técnicas de ecología de paisaje, la distribución de los campos abandonados y las formas en que la colonización vegetal los va colonizando, en función tanto de las características de los suelos y de las crecientes dificultades para el pastoreo y la ruina de los bancales en las pendientes por su gran fragilidad frente al abandono pese a que guardan los mejores suelos. En suma, un paisaje potencialmente muy rico desde el punto de vista agronómico, y sobre todo cultural y patrimonial del que se nos ofrece una cartografía y un estudio ecológico detallados, pero con menor incidencia en los procesos sociales.

El contrapunto más reciente de la primera generación de estudios sobre los procesos de cambio se puede encontrar en un proyecto de investigación sobre montañas de la mitad septentrional ibérica dirigido por Carmen Delgado Viñas, de la Universidad de Cantabria, y Juan Ignacio Plaza Gutiérrez, de la de Salamanca (Delgado y Plaza, 2012). Se han publicado en un solo libro los estudios, según un programa común, de diferentes autores correspondientes a 17 comarcas montañosas, cuatro de la Cordillera Cantábrica, tres de los Montes Vascos y Pirineos occidentales; otras tres del noroeste ibérico; dos de la Cordillera Ibérica, el enlace entre el sistema Ibérico y el Central en Ayllón, tres más del macizo de Gredos y las Villuercas cacereñas. Faltan en la recopilación, por el ámbito del proyecto, todas las montañas meridionales, pero algunos trabajos como el de Gómez Moreno sobre la montaña malagueña (1999) pueden ayudar a suplirlo.

Aun constatando que en la enorme mayoría de los casos las pérdidas continuadas de población han conducido a poblaciones muy envejecidas y masculinizadas y densidades en el umbral de la desertización (que se suele fijar en 10 habitantes por $\mathrm{km}^{2}$ : la Cabrera leonesa, las Tierras Altas sorianas, la sierra de Ayllón y la Serrota abulense, son, de las estudiadas, las que están por debajo del $5 \mathrm{hab} / \mathrm{km}^{2}$ ), los directores han podido distinguir entre espacios con absoluto estancamiento y notable permanencia de rasgos tradicionales (Somiedo, Alto Sil, montaña Alavesa, Montes de León, la Cabrera, Sanabria...) en que apenas se advierten algunos tenues signos de revitalización sin que la población vinculada no residente logre cambiar la situación por ser flotante o demasiado estacional; algunas zonas en donde predomina la regresión pero la revitalización ya es más perceptible, fundamentalmente por determinados tipos de turismo (valle de Asón, Gredos y Villuercas) o industrias de la madera (Tierra de Pinares); y finalmente, algún caso como el de Hernio, en Guipúzcoa, donde el saldo vegetativo es ya positivo.

En términos generales, por tanto, llama la atención hasta qué punto las dinámicas negativas permanecen, más de medio siglo después de iniciarse, y cómo se hacen patentes las disfunciones entre la pérdida de población, desplazada en el mejor de los casos hacia las cabeceras comarcales, y la permanencia de unas estructuras físicas más o menos arruinadas: los asentamientos tradicionales 
(barrios, aldeas) están desapareciendo, las explotaciones reduciéndose y borrándose en parte la organización tradicional que daba mosaicos de paisajes en función de la complementariedad agropecuaria entre prados cercados y terrazgos cerealistas, a veces campos construidos en las pendientes con bancales. La conclusión de los autores es clara: no se trata tanto del declive de los modelos tradicionales como de la falta de cohesión y la mala adaptación a los nuevos contextos, a pesar de la aparición de un sector de servicios, por distintas razones desequilibrado, y de la nueva población, por su carácter no residente y su finalidad.

\section{VAlLeS anegados. Una Geografía de las ausencias}

De entre los recursos excepcionales de las montañas, está el que sean «castillos de agua», como expresivamente dijo Martínez de Pisón, reserva hídrica para la llanuras y las ciudades. El Informe de la Comisión recoge este significado estratégico de las zonas de montaña en su primer punto («fons vitae»), territorios donde nace la vida de la que son expresión los ríos. Pero esta función, en un país de tan desaforada política hidráulica en los años centrales del siglo pasado, en que la construcción de embalses concebida en la República se materializó durante la Dictadura exclusivamente como instrumento de crecimiento, está muy lejos de haber supuesto para las zonas de montaña alguna ventaja, alguna contrapartida.

Todo lo contrario. Cabero habló, ya lo he mencionado, de «embalses de la minería» para expresar el carácter extractivo con que se plantearon las ejecuciones; Pisón evocó los pueblos deshabitados como consecuencia del rosario de embalses que anegaron sus fondos. El alcalde de Biescas recordó algunos de esos pueblos abandonados: Búbal, Saqués y Polituaraú expropiados por completo para la construcción de la presa de Búbal. El alcalde de Prioro, a ocho km de Riaño, fue quizá el más expresivo: pusieron «pantanos a degüello», desestructuraron todos los valles y echaron a la gente. «Los pantanos fueron una debacle para las montañas [...] ser zona deprimida y que encima te pongan ahí, no ya un pantano, sino varios y consecutivos (...)»

El pantano de Porma (uno de aquellos a los que se refería el alcalde de Prioro), llamado ahora Juan Benet, en honor del ingeniero y escritor que lo construyó, está asociado como es sabido a una intensa historia literaria. En él escribió Benet (al menos en parte) Volverás a Región, ese mundo inextricablemente unido a la obra del escritor -al mismo título que el Combray de Proust o el Macondo de García Márquez-, ese universo fabulado pero que resulta de transfiguraciones de escenarios geográficos concretos, de tal forma que las huellas de la realidad se convierten en puntos de referencia. Se da la circunstancia que el embalse de Porma anegó el pueblo de nacimiento de Julio Llamazares, 
Vegamián, y le suscitó la escritura de su novela más famosa, La lluvia amarilla, ese monólogo terrible del último habitante del pueblo Ainielle del Pirineo aragonés, que recuerda de forma algo extraviada a los que se han ido, a los que se han muerto, en el momento final de su supervivencia desolada.

Por lo que la cuestión ha vuelto a tomar actualidad es porque Llamazares acaba de publicar un nuevo libro (Distintas formas de mirar el agua) volviendo, ahora sí, al escenario de su infancia, Vegamián, pueblo sumergido entre otros por el pantano de Porma. A la vista de la anécdota contada por Llamazares [Benet le habría dicho, no sin provocación, que en suma era escritor gracias a él, lo que el leonés tomó entonces por un insulto, pero ahora le ha servido de detonante para emprender la narración], resulta bastante interesante contraponer los dos universos paisajísticos y perceptivos que de la montaña leonesa tienen ambos autores. No pueden ser más distintos.

El mundo de Benet es el de la montaña hostil, miserable, inabarcable, incomunicable, un laberinto en ruinas desasosegante. El viajero que sale de Región para ir a su sierra tiene que atravesar un desierto por caminos de manada que siguen a los ríos entre murallas inexpugnables. Es el encuentro de la Cantábrica con el macizo Galaico-Portugués, el estrellamiento de calizas hercinianas plegadas contra el macizo asturiano que funciona a modo de yunque. Todo geógrafo (o geólogo) que no lo haya hecho debería leer las páginas 36 a 43 de la edición de Destino de 1967 en que se contiene una minuciosa presentación de las (supuestas) estructura y morfogénesis de la Sierra de Región, apoyada en referencias nominales a veces reales (Babia, Montes Aquilanos, etc...) y, desde luego, con potentes recursos metafóricos.

Pero lo que interesa aquí es la evocación de una montaña hostil en todo y por todo: primero, sin enlace transversal entre los caminos, de modo «que la comunicación entre dos valles paralelos ha de hacerse, durante los ocho meses fríos del año, a lo largo de las líneas de agua hasta su confluencia, y en sentido opuesto» (Benet, 1967: 7). Para desesperación, pienso, del ingeniero. Después, porque donde la vegetación no es rala y desértica, es decir en los fondos de los cañones, resulta intransitable de puro lujuriante [«bosques de helecho gigante, y fosos infranqueables rellenos de acebo, viburno y yerbabuena» (Ibid: 43)]; todo ello por razones climáticas: «si la tierra es dura y el paisaje es agreste es porque el clima es recio: un invierno tenaz que se prolonga durante ocho meses»; a lo que hay que añadir que se trata de una tierra de pastores, «de ganadería ridícula y con una mesta arcaica», a base de puros desengaños agrícolas; y unos bienes de propios que al ser arrebatados a «comunidades abúlicas», fueron adquiridos en pública subasta por los mismos y lejanos potentados que ya habían comprado los bienes eclesiásticos. De modo que el burgo es «una agrupación de enfiteutas temerosos unos de otros, asediados todos por la hostilidad de la geografia, la historia, la geología, la climatología y la mesta, dispuestos a resistir el sitio y 
mantener su estatus tanto para defender una economía paupérrima como para alimentar el miedo que inspira toda emigración y todo cambio de su condición y de sus lares». (Ibid: 49)

Frente a esta descripción implacable, Llamazares en su libro sobre «el pantano de Benet» presenta la memoria de unas tierras de montaña, si no las de una Arcadia feliz, manejables y comprensibles para sus pobladores. Los miembros de una familia van juntos al pantano que ha sumergido Vegadián, a arrojar las cenizas del patriarca, que ha sido marido, padre y abuelo, y cada uno evoca su propia memoria en ese nuevo paisaje, hermoso y silencioso, a la vez lleno de paz, pero, para la mayor parte de los protagonistas, también lleno de desolación. Desde los coches, en el camino, el pantano ha ido apareciendo a cada revuelta, a medida que iban pasando los pueblos semiabandonados, salvo Boñar, «en los que ya no queda nadie de menos de 45 años, no ha nacido nadie después del momento en que fueron anegados.»

Es curioso que Virginia, la abuela, la que más vivió allí porque se fue a los cuarenta años, recuerde sobre todo la desorientación que les produjo la llegada a la laguna, a unos barracones de uralita preparados para acogerles, porque el poblado estaba todavía sin construir: «quince o veinte familias procedentes de lugares anegados como el nuestro, a aquel fangal infinito emergido de la desecación del lago»». A todos ellos, procedentes de las montañas, les costó acostumbrarse a los nuevos horizontes y a la falta de accidentes geográficos que les sirvieran para orientarse en la llanura. También les costó aprender una agricultura que desconocían totalmente, en una tierra tan feraz que abría multitud de posibilidades de cultivo, mientras que en la montaña se limitaban a las patatas, algo de trigo y centeno, y sobre todo tenían el pastoreo. Reconoce la viuda que quizá con el tiempo mejoraron, pero que nunca dejaron de añorar su vida anterior. Aunque la hija mayor, Teresa, que se fue a los 16 años, recuerda bien las dificultades económicas que pasaron los padres, a los que no les bastó el dinero de las indemnizaciones sino que tuvieron que hipotecarse. $\mathrm{Y}$ es ella la que formula una de las ideas centrales que Llamazares quiere transmitir, una comparación a mi juicio quizá excesiva: se fueron como los judíos españoles, conservando las llaves de las casas como si fueran a volver.

El nieto Alex, ingeniero, saca las conclusiones más claras: el progreso no lo justifica todo, fue una atropello, pagaron las fincas a la mitad de lo que valían, y las eléctricas no dejan nada. «No ha cambiado nada en el paisaje hasta que decidieron cambiarlo todo» reflexiona otra nieta. Mientras un tercero, más joven, se resiste a arrastrar un resentimiento y una tristeza que no le pertenecen. «Esto no es la Arcadia feliz, piensa, pero si la abuela hubiera permanecido aquí habría tenido una vida más feliz que en la laguna.» Pero al igual que el padre es el protagonista ausente, en el día en que toda la familia traslada sus cenizas al lugar que lo vio nacer y al que siempre se había negado a volver, el paisaje 
del embalse también permanece mudo, solo se oye el sonido del agua. «iQué bonito, pero qué triste!», piensa Teresa. Quizá sea un buen resumen de esa geografía de la memoria, de una geografía de las ausencias y de las desapariciones.

Al margen de estas miradas literarias tan lejanas una de la otra, no solo por el tiempo transcurrido, y volviendo a la Comisión del Senado para las zonas de montaña, varios intervinientes suscitaron las cuestiones de compensación y justicia territorial respecto al agua. Las empresas hidroeléctricas tendrían que tributar en las zonas de montaña, lo mismo que los otros recursos de ella extraídos, energéticos y no energéticos, todos los monetarizables, incluida la explotación de la fauna. El diputado provincial de Albacete y presidente de la mancomunidad de la Sierra del Segura puso de manifiesto que entendía como una paradoja que «se paga[ra] por no emitir, y no se paga[ra] por ser el pulmón», y se llegó a plantear de forma retórica la vieja pregunta de principios de la ecología política: "¿de quién es el viento que circula? [entiendo] que se [deben] repartir de forma comarcal los beneficios que reporta la energía.» Por ello se declaraba partidario de una discriminación positiva a favor de la montaña, lo que llamó «favoritismo justo».

La Federación Nacional de Asociaciones y Municipios con Centrales Hidroeléctricas tiene como objetivo defender los legítimos intereses de las entidades con este tipo de instalaciones y conseguir que tributen en ellos. La Comisión, en su Informe, no llega a pronunciarse de forma explícita al respecto, pero sí alude a medidas de discriminación positiva a favor de las zonas de montaña, y a reconocer su papel en la lucha contra el cambio climático. Sin caer en maximalismos, parece necesario de una vez por todas hacer una valoración cuantitativa de las riquezas naturales y ambientales en la contabilidad pública (y en la economía de mercado), de lo que aportan las zonas de montaña a otros territorios, de las externalidades positivas, para poder plantear con fundamento y sin demagogia, cuestiones de solidaridad, equidad y cohesión territoriales. Probablemente será eficaz a efectos jurídicos y económicos. Pero seguro que nada puede hacer para resolver los sentimientos de desgarro producidos en la vida de las personas expulsadas de sus lugares y privados de sus medios de vida y de sus costumbres.

\section{LA DIMENSIÓN ECOLÓGICA, TERRITORIAL Y PATRIMONIAL DE LA MONTAÑA}

El vaciamiento poblacional y la desorganización productiva que han afectado a las zonas de montaña tienen, por su carácter general y extensivo, una gran relevancia territorial: afectan en España a unos $200.000 \mathrm{~km}^{2}$, el $38 \%$ de la superficie del país, distribuidos en 2.868 municipios, el 35\% del total, en los que ahora solo vive el $8 \%$ de la población. Ya se ha hablado de la escala más general del problema. 
Pero hay que considerar también la dimensión territorial de la montaña a escalas distintas de las hasta ahora comentadas. Todos los comparecientes, desde luego todos los geógrafos, coincidimos en exponer ante la Comisión la idea de que con el abandono (o expulsión) de la población, se han desarticulado unos territorios de montaña cuya organización mantenían las economías tradicionales, fundamentalmente por la complementariedad de los usos ganaderos y agrícolas y la trashumancia, de corto o largo radio, ya que las cañadas contribuían a articularlos. La montaña da lugar por sus características físicas a unos gradientes ecológicos que determinan la organización de los ecosistemas. A su vez, la organización tradicional de los aprovechamientos, con los terrazgos y los prados cercados en los fondos de valle, las vertientes boscosas y las brañas y majadas de altura para el pastoreo estival, respeta con carácter general esa distribución ecológica. La montaña tradicional suponía, pues, desde el punto de vista territorial y ecológico un sistema estable de equilibrio, entre cumbres, vertientes y valles, en el que los usos del suelo se ordenaban según la altitud, constituyendo unidades paisajísticas relacionadas entre sí, de modo que la alteración de una de ellas repercutía (sigue repercutiendo) sobre el conjunto. Eran, y son, unidades territoriales y ecológicas que deben ser gestionadas desde una consideración integral.

Son las partes bajas y las montañas medias las de paisajes más desfigurados. Pero todo el sistema se desequilibra. Con la desaparición de la ganadería (la gran modeladora de paisaje) y los cambios de cabaña (en el Norte ibérico a favor del vacuno de carne), también con el descuido de las masas forestales, particularmente de las repobladas, de los caminos de herradura y vías pecuarias, así como el abandono de tierras de cultivo y de sus infraestructuras como bancales, terrazas y redes de riego, se produce la entrada de matorral y de monte bajo arbóreo. Para este proceso de revegetación espontánea, se usa en Francia, un concepto de origen ecológico: fermeture du paysage, cierre del paisaje, contra el que se lucha con programas nacionales, regionales y locales. Los riesgos de esta colonización del matorral son evidentes: fundamentalmente aumentan el riesgo de incendio, pero también empeoran la calidad de los pastos, los caminos se vuelven impracticables, las construcciones son devoradas por una vegetación colonizadora, y desde luego disminuye la calidad territorial y paisajística, se contaminan las cuencas visuales. El alcalde de Peñarrubia en Cantabria puso de manifiesto alguna de las paradojas del proceso acaecido en las montañas. Contó que han tenido que llevar ovejas de Andalucía para que se coman especies invasoras; y ello porque de la montaña cántabra han ido desapareciendo ovejas y cabras, por su incompatibilidad con la proliferación de lobos, como consecuencia de la despoblación, de la pérdida de actividad pero también, en su opinión, de las medidas de protección. «Nos gastamos cientos de millones en desbrozar los montes, cuando eso lo hacían [antes] las cabras y ovejas expulsadas por la 
proliferación de lobos, zorros». Ya he comentado el análisis detallado que hace Lasanta del fenómeno de colonización vegetal en la sierra de Cameros Viejo.

Lo que lleva a una cuestión recurrente en las sesiones, la aparente sobreprotección ecológica y ambiental y la supuesta desatención en contrapartida de las necesidades de las poblaciones; la mayoría de los responsables municipales subrayaron contradicciones en las políticas, casi siempre refiriéndose a la sobrepoblación de animales dañinos para sus rebaños, pero también las incongruencias de las políticas de plantación y de protección de especies. «Se cortaron sabinas [de la Tierra Muerta conquense] para plantar pinos, luego se las protegió, y ahora se dice que hay demasiadas sabinas. No se pueden proteger las cosas por modas», manifestó un alcalde de la serranía de Cuenca. Mientras el alcalde de Candín se quejaba de los problemas que les acarreaba ser una de las zonas más reguladas y protegidas de España, afectada por casi todos las disposiciones ambientales: más de diez figuras de protección desde la Red Natura 2000, pasando por ley de la Espacios Naturales de Castilla y León y el PORN de la Sierra de Ancares, a la protección del urogallo y del acebo.

Muchos representante de municipios de montaña se quejaron, y es algo que hay que tener muy en cuenta, de la forma en que se hace la declaración y, sobre todo, la gestión de espacios naturales protegidos que entrañarían muchos inconvenientes para los habitantes. Es preocupante que algunos opinen que a mayor valoración ambiental, mayor marginalización de la zona. Jaime Izquierdo, vinculado a los medios ambientalistas asturianos y gran defensor del papel económico que debería desempeñar la ganadería extensiva, resumía la tensión existente con estas palabras: «Esto [el paisaje, la montaña] estaba antes peor conservado pero mejor atendido». Mientras el experto europeo Nicolas Evrard mantenía que no es posible el buen estado ecológico sin contar con la colaboración y la complicidad de sus habitantes.

Sería aconsejable no contraponer protección a producción y evitar a toda costa que se entienda proteger como sinónimo de prohibir. Martínez de Pisón insistió ante la Comisión en que hay que eludir la disyuntiva entre todo conservación en las reservas o en los parques, y todo deterioro en el resto; para ello es necesario que las acciones y respuestas sean territoriales, que cada caso particular tenga una solución propia, aun cumpliendo unos objetivos generales. Por ejemplo, a ningún efecto se debería dejarse arrastrar por la posible división administrativa entre vertientes de una montaña. El propio Martínez de Pisón, encargado en su día de elaborar el Plan de Ordenación de Recursos Naturales para la creación del Parque Nacional de la Sierra de Guadarrama (Martínez de Pisón, 2009), puso de manifiesto hasta qué punto la división de competencias entre las comunidades de Castilla-León y Madrid había retardado el proceso y dificultaba la gobernanza. De la misma manera que se deberían trascender las fronteras en las montañas ibéricas, aspecto muy bien advertido por Cabero, que 
propuso la declaración como villa ibérica con dos barrios del pueblo de Rihonor en Castilla, y Rio de Onor en Portugal. Recuperar en las zonas transfronterizas la accesibilidad de la frontera, la cooperación entre dos países, permitiría defender un uso más finalista en la montaña de los fondos europeos de frontera.

En línea con estos argumentos, la comisión senatorial en su Informe propugna la «necesaria y razonable» alianza entre conservación y desarrollo, la recuperación de espacios naturales de montaña a la vez que la generación de empleo estable tanto en actividades tradicionales como en otras de nueva introducción. En su Recomendación segunda, insiste sobre que en los parques y reservas hay que fomentar la permanencia de la población local y el empleo, al tiempo que reconoce la importancia del paisaje del patrimonio natural y cultural. Para lo cual, las más importante sugerencias son de orden fiscal.

Pero además de lo anterior, lo importante del Informe del Senado es que plantea de forma terminante una estrategia para las zonas de montaña con perspectiva integral, persiguiendo una renovada interdisciplinariedad en el acercamiento al territorio, la transversalidad de las políticas y principios administrativos, un trabajo en red de las administraciones desde los municipios de alta montaña a la Unión Europea, la convocatoria a la labor de colectivos de población, jóvenes, mujeres, inmigrantes, familias la superación de la reduccionista consideración urbanita del mundo rural: «Por todo ello desde el conjunto de las administraciones públicas se deben impulsar acciones de sensibilización del medio urbano hacia las zonas rurales, en especial las zonas de montaña, siguiendo el ejemplo de las iniciativas de la denominada 'ingeniería territorial' impulsadas en países como Francia (Senado, Informe, 2015: propuesta decimotercera).

Ingeniería territorial que se debe basar en primera instancia en «visualizar la realidad de cada territorio», atendiendo a la diversidad del medio, de manera que su ordenación responda a necesidades concretas de gentes y territorios, para dotarlos de los servicios y los equipamientos necesarios. En segunda instancia, se apoya para las zonas de montaña el establecimiento de «contratos territoriales» por parte de la administración con titulares de las explotaciones para, como señala el R.D 1336/2011, orientar la actividad de la explotación a la generación de externalidades positivas que contribuyan al desarrollo sostenible del medio rural.

Volviendo a la escala regional, el vaciamiento poblacional de las montañas y su desorganización da lugar a situaciones críticas de falta de cohesión territorial. Por comparación, el consejero de la Comunidad aragonesa reclamaba que se les diese a las montañas una consideración al menos similar a la de las Confederaciones Hidrográficas. Y no faltaron los que advirtieron que un país necesita cohesión territorial -lo que, por otra parte, es doctrina europea- y no se puede construir sobre grandes vacíos poblacionales. El problema trasciende lo sectorial y lo local para pasar al dominio de la continuidad territorial: «una 
sociedad sana no puede asentarse sobre territorios desintegrados», afirmó Eduardo Moyano, ingeniero agrónomo y catedrático de Córdoba. Este es además uno de los objetivos de la Agenda Territorial Europea 2020 (UE, 2011) aprobada en 2011 en la reunión de los ministros responsables de la ordenación del territorio que apostaron por la integración, desarrollo y sostenibilidad a partir de «regiones diversas».

\section{UN FUTURO PARA LAS ÁREAS DE MONTAÑA}

Hay una cuestión que ha aparecido una y otra vez en el transcurso de las sesiones del Senado y se refiere a si se necesita en España una ley de Montaña de ámbito estatal. Los países que tienen explícitamente a las montañas en sus textos constitucionales y en su marco legal han tenido hasta ahora más éxito en sus políticas. Es el caso de Francia con una ley de Montaña de 1985, modificada en 2005 (que les dedica el $15 \%$ de los fondos que recibe de la PAC y financia a los jóvenes agricultores en ellas con el 75\% de los costes de explotación); el de Italia con su ley de 1996; a las que hay que añadir, fuera de la Unión Europea pero en país particularmente eficaz al respecto, la ley suiza de inversiones en regiones de montaña de 1974. En el caso de España, la Constitución de 1978 menciona en el artículo 130.2 la necesidad de dispensar un tratamiento especial a las zonas de montaña, con el fin de lograr equiparar el nivel de vida de todos los españoles. En contrapartida, la única ley específicamente aplicable es la 25/1982 de Agricultura de montaña, que fue objeto, por cierto, de recursos por parte de algunas CCAA, por entender que su artículo 5 sobre la definición por el Estado de las áreas de montaña invadía sus competencias. Por su parte, Cataluña sí tiene aprobada desde 1983 una ley de alta montaña.

El sentir mayoritario de los comparecientes parece ser que (ya) no es indispensable una ley general, y que más bien, hay que podar leyes, eliminar obstáculos y desarrollar y aplicar la Ley para el Desarrollo Sostenible del Medio Rural de 2007, que quedó paralizada por falta de fondos, y que es necesaria para poder cumplir con la Agenda 2010-2020. De ella se han criticado los umbrales que establece para definir medio rural, pero, en cambio, es muy apreciable la voluntad demostrada de trascender las carencias de un modelo esencialmente agrarista y la de buscar una mayor relación de complementariedad entre el medio rural y el medio urbano. En este sentido, la ley prevé unas acciones y medidas multisectoriales concibiendo un mundo rural cada vez más diversificado y con un elevado grado de gobernanza. Aunque no lo dice expresamente, el Informe de la Comisión parece sumarse a esta opinión al no plantear la posibilidad de una nueva ley y sí recomendar la dotación suficiente para aplicar de modo efectivo la ley de Desarrollo Sostenible de Medio Rural. Por otra parte, en la propuesta decimoctava del Informe, al hablar de la necesidad de cambio 
de modelos productivos y de la necesidad de que sean cada vez más virtuales y admitan deslocalizaciones, el Informe reconoce el éxito que está teniendo Suiza al respecto, al igual que Francia con la institución de los Comités de Macizos, así como el papel desempeñado por los comités comarcales catalanes. «Experiencias que responden a una visión sinérgica y holística, ejemplo de convivencia entre ámbitos competenciales diferentes, con el punto de mira en el territorio y no en el ámbito sectorial».

Otra cuestión previa a las propuestas activas para los medios de montaña que ha sido suscitada repetidas veces, es el marco administrativo más adecuado para la prestación de los servicios indispensables en zonas de poca población y de difícil acceso. Es evidente que la mayor parte de los servicios sociales, sanitarios, educativos, de dependencia, deportivos, etc. necesitan unos umbrales mínimos de población que muchos municipios de montaña no alcanzan. Y en este contexto aparece la disyuntiva sobre si, para suministrarlos, es mejor la comarca o la diputación provincial, o en su caso las mancomunidades municipales. Es evidente que no hay acuerdo sobre la cuestión y que las diferencias son regionales; Cataluña y Aragón, que tienen tradición comarcal, se muestran mucho más favorables a la comarcas (el Informe retiene el buen funcionamiento de los «consells comarcals» catalanes), mientras las dos Castillas, Andalucía y Comunidad Valenciana están más decantadas por el mantenimiento de la diputación provincial. El consejero de Agricultura, Ganadería y Medio Ambiente de Aragón mantuvo que había que fortalecer las comarcas como elementos dinamizadores y coordinadores; por su parte, el alcalde de Yunquera en Málaga afirmó que la comarca no les había ayudado mucho, y que la mancomunidad de la Sierra de las Nieves se había convertido en un núcleo de acaparamiento de poder. En el mismo sentido el diputado de Albacete se manifestó a favor de las diputaciones por reconocerles la prestación de servicios, incluido los urbanísticos, a través de convenios y consorcios con los entes locales. De modo que está lejos de haber unanimidad. En este orden de cosas, una autoridad institucional castellanoleonesa mostró su desacuerdo con la ley de Racionalización y Sostenibilidad de la Administración local, por establecer un coste estándar por persona, lo que jugaría, en su opinión, en contra de territorios amplios y de muy baja densidad de población, como los de su Comunidad. Precaución recogida por la Comisión en su Informe que advierte que se debe analizar con cuidado el impacto de esta ley en los municipios de montaña.

El futuro de las áreas de montaña pasa -ya se ha dicho- por hacerlas visibles, por estudiarlas, cartografiarlas, por escuchar a los que están en ella, por que sean apreciadas en su singularidad e integridad. «No es imaginable, sostuvo Carlos Pinto, presidente de la Asociación Europea de Autoridades Políticas de Regiones de Montaña (AEM), una política general para la montaña, sin tener en cuenta los sistemas montañosos y las características de cada zona». Lo que 
entraña, por una parte, el reconocimiento explícito de la especificidad de las montañas y, por otra, su identificación, representación e interpretación.

La reforma de Lisboa 2007 del Tratado de la Unión Europea permitió incluir como artículo 174 explícitamente a las regiones de montaña en el conjunto de las que padecen desventajas naturales o demográficas graves y permanentes. Los representantes de le AEM comparecientes ante la Comisión le daban a esta inclusión una gran importancia para el objetivo de llevar a cabo la Estrategia Territorial de la Unión. Lo que se iniciaría con la culminación del reconocimiento de las unidades de montañas de acuerdo con la Carta Europea de las Regiones de Montaña y la cartografía de los macizos prevista ya hace más de un decenio.

Sirviéndome de una muy sensata clasificación propuesta por los expertos europeos se pueden señalar tres ejes de intervención en las montañas: compensaciones, creación de infraestructuras y dotación de servicios, y un eje cultural de apoyo a la identidad y defensa del patrimonio. Parece evidente que se deben manejar de forma complementaria y no excluyente. Empezando por las compensaciones, han sido muchas las actuaciones sectoriales realizadas en España en todas las CCAA pero el único aspecto que se ha trabajado conjuntamente ha sido el de las indemnizaciones compensatorias, mediante el mecanismo de apoyo a las explotaciones agrarias en municipios de zona de montaña. Este trabajo resulta insuficiente por varios motivos entre los que sobresalen: primero, la definición de las áreas de montaña; y segundo, el que no atienda bastante a la pequeña explotación ni a la ganadería extensiva. En el año 2006 se elaboró por la dirección general de Biodiversidad del entonces ministerio de Medio Ambiente, un borrador para la definición de zona de montaña y el estudio de la aplicación de la indemnización compensatoria. Aunque con un criterio ecológico más que territorial, se avanzaba bastante en la cartografía a partir de una distinción entre «montañas», definidas por sus gradientes ecológicos, y «zonas de montaña», siendo estas últimas los territorios continuos y extensos donde se dan condiciones de montaña en función de variables descriptivas y determinados umbrales. No se ha avanzado después en los trabajos.

Hubo en las sesiones de la Comisión una actitud favorable a los incentivos fiscales para compensar en el sentido constitucional las dificultades añadidas. En relación con los fondos de la PAC se ha repetido varias veces que sirven de apoyo a la agricultura y a la ganadería pero sobre la base de explotaciones demasiado grandes para las que suelen darse en la montaña. El representante de la Unió de Pagesos de Catalunya puso de manifiesto que, aunque en los nuevos fondos Feder se incrementen las cantidades a percibir por hectárea, no se discrimina a favor de los profesionales de las explotaciones, lo cual les perjudica. $\mathrm{Y}$ en el mismo sentido mantuvo que España sigue sin hacer uso de la figura del agricultor activo, sí utilizada en otros países; esta preocupación ha sido recogida 
en el Informe que opta en el punto decimoséptimo por recomendar que se potencie esta figura y que se concedan incentivos fiscales a quien obtenga más del $50 \%$ de sus ingresos en la actividad agraria y resida en zona de montaña. Entre otras medidas fiscales recomendadas está también el impulsar los beneficios en el IRPF, impuestos de sociedades, autónomos, módulos en I+D.

En cuanto a políticas de desarrollo se ha hablado en la Comisión de muchas cosas: acoplar la ganadería extensiva a la PAC; tomar medidas de política forestal de diversa índole pero que todas pasan por la explotación in situ de la madera y la limpieza de los bosques y utilización de residuos para producir biomasa; desarrollar el transporte público, y relacionarlo con el turismo. El alcalde de Buenache manifestó que nunca había habido tanta riqueza forestal en la Serranía de Cuenca como ahora y, sin embargo, nunca había sido tan desaprovechada. El de Santisteban del Puerto de Sierra Morena, se escandalizaba con que se considere el 50\% del territorio andaluz forestal, y sin embargo solo aporte el 2\% de la producción final agraria: lo achacaba a lo mal que se entienden los productos del monte mediterráneo, y a lo mal que se les añade valor. Subrayó que son empresas y empresarios vascos los que van a procesar la madera y que las empresas de aprovechamiento energético están radicadas en Madrid y Navarra. Hay muchas posibilidades, concluyó: fabricación de madera, biomasa y pellets, extracción de corcho, aprovechamiento resinero, ganadería, turismo rural, plantas aromáticas y, desde luego, la caza. Sería necesario crear un gran centro de formación en las profesiones mencionadas para dar trabajo en un sistema alternativo al del subsidio, de modo que los jóvenes no se desmotiven. El Informe de la Comisión recoge y amplía todas estas propuestas: desarrollar agroindustrias de calidad, actividades vinculadas a los espacios naturales protegidos en el interior de estos, aplicar criterios de mejora fiscal para el emprendimiento en montaña, gestionar el bosque tratando de que el valor añadido permanezca dentro del territorio, formación especializada en profesiones próximas al territorio y relacionadas con el monte, como prevención de incendios, reforestación, limpieza, custodia de especies protegidas, industrias del corcho; y singularmente, en este capítulo, una estrategia para el impulso del recurso de la biomasa; recuperación de actividades tradicionales, de la arquitectura tradicional y de la arqueología industrial.

Como no podía ser de otra manera las ventajas y limitaciones del turismo de montaña han sido tratadas ampliamente en casi todas las intervenciones y debates. Resultó llamativo que el primer compareciente fuera el consejero de Presidencia de Aragón y también presidente del grupo Aramon, Montañas de Aragón, participado por la administración regional al 50\%. Sostuvo que el turismo de nieve y aventura que representa cerca del 12\% del PIB aragonés, es realmente la única alternativa eficiente para evitar la despoblación de las montañas. Las restantes intervenciones, referidas o no explícitamente a Aramon, se mostraron por el contrario más partidarias de mantener el turismo de nieve 
dentro de unos límites razonables y no perjudiciales. El Informe a su vez se apuntó a estas cautelas optando con fuerza por el desarrollo del turismo vinculado al patrimonio natural y cultural.

Íntimamente unido con el desarrollo del turismo está la cuestión de la movilidad y de los transportes. Desde luego se defendió el imprescindible desarrollo del transporte para vertebrar el territorio, pero también la mejora de las infraestructuras viarias y ferroviarias, así como de los elementos necesarios para una movilidad básica de las poblaciones. Ofreció particular interés la intervención del presidente de la Asociación para la promoción del transporte público que sostuvo que para cualquier futuro sostenible en montaña, había que plantearse modelos de movilidad alternativos y justos; asimismo recomendó, en línea con la gobernanza, confiar la gestión a gestores locales, usuarios, amigos del ferrocarril, etc.

Respecto del patrimonio, algunos expertos se pronunciaron a favor de volver a los modelos productivos «inteligentes» del pasado. El arquitecto José María González, Peridis recordó, como experto en la gestión del patrimonio, una frase de Enrique Fuentes Quintana: «El patrimonio de antaño son las rentas de hogaño»; en este sentido mantuvo que la verdadera oportunidad de las zonas de montaña son los montes, el paisaje, el patrimonio: «tenemos que inventar[les] valor añadido». Se habló de la posibilidad de turismo de trashumancia y de revitalizar las formas de gestión comunal, consideradas por algunos como la mejor manera de gestionar amplios territorios. Más que reliquias los comunales («los delicadísimos y variados comunales españoles», dijo Jaime Izquierdo) deberían entenderse como patrimonio a defender de leyes normalizadoras de administración local. En este sentido, en cambio, el Informe no ha ido más allá de la gestión de los «Montes de Socios», dado que sus Juntas gestoras habían puesto el acento en la fijación de la población.

Sea como fuere, lo que es evidente es que lejos de seguir asistiendo desde fuera y desde dentro a la muerte de la formas de vida en la montaña, a la degradación de sus paisajes y a la desaparición de sus recursos se postulan modelos alternativos con el desarrollo de políticas activas y positivas. Nada puede cambiar de verdad en el destino de los territorios de montaña, no pueden tener futuro y atraer a nueva población que fije en ellos su residencia, sin dotarles de infraestructuras, equipamientos, servicios y movilidad; también y sobre todo de conectividad: en esto el Informe de la Comisión es terminante, hace falta acceso a las nuevas tecnologías, a internet de banda ancha, en condiciones suficientes para salvar la brecha digital en las áreas de montaña.

Las intervenciones de los cargos directivos de la AEM fueron reconfortantes porque presentaron modelos europeos de áreas de montaña que están teniendo éxito en captar nueva población activa, en generar flujos de inmigración, y a la vez en conservar el patrimonio, entre otras cosas, dijo Evrard, porque se atiende 
a que se mantengan intercambios y vínculos intergeneracionales para la transmisión de los saberes, de los valores y de las experiencias: valle de Aosta con programas específicos, Saboya, el caso de Puy du Dôme y la falla de Limagne con capital en Clermont Ferrand y su apuesta por la ganadería extensiva, zona que se ha reinventado en relación con su candidatura a patrimonio mundial, y también muchos casos pirenaicos. El caso suizo es expresivo: hasta aproximadamente el año 2008 las políticas públicas consistían ante todo en compensar las dificultades naturales. Pero se produjo entonces un cambio de paradigma: se procedió a estudiar los cantones para saber cuáles eran sus bazas, sus puntos fuertes y se reorganizó la cooperación y los servicios de forma discriminada. Se crearon centros de innovación y de excelencia en sectores basados en lo rural. En el caso de Valais por ejemplo, se ha trabajado con este orden de prioridades: energías renovables e hidroelectricidad, tecnologías de la información y de la comunicación, solo en tercer lugar el turismo, después plantas de montaña y química. Se trata de experimentar nuevas formas en el mercado laboral, del género «flexiseguridad», que suponen flexibilidad pero también condiciones sociales que permitan una cierta carrera profesional. A nuestros efectos hay que trabajar en la especificidad de los macizos, elegir objetivos específicos a nivel local y regional y vincularlos a los objetivos generales de las políticas europeas.

En ese horizonte, no está de más trabajar con territorios macrorregionales. Se ha hablado ante la Comisión de algunos éxitos europeos, el Báltico, el arco Alpino, la cuenca Adriática. La Comisión se hizo eco de proyectos ibéricos de este tipo, por ejemplo el de la Serranía Celtibérica: está financiado por el ministerio de Agricultura y fondos Feder, involucra a las CCAA de Aragón, Castilla y León, Castilla la Mancha y Valencia, y afecta a toda la zona de más de $700 \mathrm{~m}$ de altitud que va desde Atapuerca hasta Morella, siendo centro de varias cuencas hidrográficas y «polo de frío» ibérico entre Teruel, Calamocha y Molina de Aragón. En Castilla y León se trabaja también a escala regional en favorecer el acceso de los jóvenes a bancos de tierra, mediante líneas de financiación de empleo joven. En otro orden de cosas, pero en ámbitos suprarregionales, se intenta promover un pacto de Estado para la demografía, al que se han sumado ya Galicia, Asturias, Castilla-León, Aragón, Castilla La Mancha, Extremadura. Existe también un proyecto pirenaico (Aragón, Aquitaine, Midi Pyrénées), pero llama mucho la atención la falta de un proyecto transfronterizo que involucre a España y Portugal. Uno de los expertos europeos sugirió la posibilidad de promover un eje mediterráneo, o bien del SW europeo, desde Portugal hasta el Macizo Central francés. En todo caso, deberíamos prestar la atención al reproche que nos hizo: España no está hablando en Bruselas como país de montañas. Es importante que lo haga.

«La montaña es la nueva frontera de Europa», se decía con entusiasmo en una de las últimas sesiones de la Comisión del Senado de medidas para evitar la 
despoblación. Los nuevos pobladores que deseen trasladarse deben encontrar en ella a la vez un proyecto de vida personal y un proyecto de viabilidad y mejora económica. Deben también aceptar un compromiso territorial y paisajístico. Probablemente, como bien señaló José Arnáez Vadillo, rector de la Universidad de la Rioja y catedrático de geografía física en la misma, el modelo del futuro no va a ser ya el tradicional, no habrá tantos mosaicos de paisajes de los que apreciamos, será más homogéneo en recursos físicos, humanos y usos. Pero, de momento, y para que haya un futuro de vida en las montañas, hay que hacer atractivo vivir en ellas, que se pueda tener porvenir económico en su entorno. El presidente de la Comisión dijo en algún momento que las montañas españolas tenían que lograr deslumbrar. El Informe emanado de estos trabajos refleja este espíritu en estos términos: entender el medio montañoso ya no como un problema sino como fuente de nuevas oportunidades.

\section{BiBLIOGRAFÍA}

Aragón Morales, F. (Dir.) Arenillas, T., Burgués, J.A., Martínez de Pisón, E., Troitiño, M.A., Arenillas, M., Jú́rez, D. (1990): Gredos, la tierra y su entorno, Ministerio de Obras Públicas y Urbanismo, 232 pp.

Benet, J. (1967): Volverás a Región, Destino, Madrid.

Bertrand, G. (1964): «Esquisse biogégraphique de la Liébana (montagne Cantabrique, Espagne) La dynamique actuelle du Paysage», en Revue Géographique des Pyrénées et du Sud-ouest, 55, 2, pp. 225-262.

Bertrand, G. (1974): Essai sur la systématique des paysages: les Montagnes Cantabriques centrales (Nord-Ouest de l'Espagne), Tesis doctoral, Université de Toulouse le Mirail.

Bertrand, G. y Cl. (2014): Del terreno al concepto. Las Montañas Cantábricas: del Geosistema al sistema GTP (Geosistema-Territorio-Paisaje). Un experiencia de 'Epistemología del Terreno' (1960-2014), Editorial Universidad de Cantabria, 69 pp.

CABERo Diéguez, V. (1980): Espacio agrario y economía de subsistencia en las montañas galaico-leonesas: La Cabrera, Ediciones de la Universidad de Salamanca. Institución Fray Bernardino de Sahagún, CSIC, León.

Calvo Palacios, J.L. (1977): Los Cameros. De región homogénea a espacio plan, Instituto de Estudios Riojanos. 2 vols.

Camarero, L. Castellano, M.L., García, I. y Sampedro, R. (2009): La población rural en España. De los desequilibrios a la sostenibilidad, Barcelona, La Caixa.

Collantes, F. (2004): El declive demográfico de la montaña española 1850-2000. ¿Un drama rural? Ministerio de Agricultura, Ministerio de Agricultura, Pesca y Alimentación

Collantes, F. (2005): «Declive demográfico y cambio económico en las áreas de montaña españolas, 1860-2000» en Revista de Historia Económica, 23, 5, 2005. 
Collantes, F. y Pinilla, V. (2011): Peaceful Surrender. The Depopulation of Rural Spain in the Twentieth Century. Cambridge Scholars Publishing, Newcastle upon Tyne, $202 \mathrm{pp}$.

Delgado Viñas, C. (2007): «Breve historia crítica y análisis comparativo de las políticas aplicadas en Europa a la áreas de montaña», Investigaciones geográficas, 42 , 35-59 pp.

Delgado Viñas, C. y Plaza Gutiérrez, J. I. (2012): Territorio y paisaje en las montañas españolas. Estructuras y dinámicas espaciales,, Ediciones de Librería Estudio, con la colaboración del Ministerio de Ciencia e Innovación, Santander, 249 pp.

ESMONTAÑA (2014): http://www.readerasturias.org/objetovideos

García Codrón, J.C. (2014): «Prólogo» en Bertrand, G. y Cl. Del terreno al concepto, pp. 11-20.

Gómez Moreno, M.L. (1989): La montaña malagueña: estudio ambiental y evolución de su paisaje, Servicio de Publicaciones de la Diputación Provincial de Málaga.

Guirado, C. y CuAdrado, S. (2009): «Los actuales procesos de urbanización y recuperación demográfica en las áreas rurales de Cataluña: los espacios de montaña (Pirineo catalán) y los espacios de traspaís litoral (Empordà), en AGE. Los espacios rurales españoles en el nuevo siglo. Actas del XIV Coloquio de Geografía Rural, Murcia.

IbáÑez MaRCILlán, M. J. (1974): El piedemonte ibérico bajoaragonés. Tesis doctoral.

LASANTA, T. (1989): Evolución reciente de la agricultura de montaña. El Pirineo aragonés, Geoforma, Logroño.

Lasanta, T. (2014): El paisaje de campos abandonados en Cameros Viejo (Sistema Ibérico, La Rioja), Instituto de Estudios Riojanos, 305 pp.

Llamazares, J. (1988): La lluvia amarilla. Novela, Seix y Barral, Biblioteca Breve, Barcelona.

Llamazares, J. (2014): Distinta formas de mirar el agua, Alfaguara, Madrid, 200 pp.

MARTÍNEZ DE PISÓN, E. (2009): «Un plan de ordenación para la Sierra del Guadarrama», Boletín de la Asociación Española de Geógrafos, 51, pp. 65-92.

MARTíneZ DE PIsón, E. (2013): «Valores geográficos de la sierra de Guadarrama», Ambienta. La Revista del Ministerio de Medio Ambiente, 193, pp. 10-25.

Molinero, F. (2001): Balance de la población (1991-2001) en Molinero, Majoral, R., García Bartolomé, J.M. y García Fernández, G., Atlas de la España rural, Ministerio de Agricultura, Pesca y Alimentación, pp. 106-107.

NAREDO, José Manuel (1971): La evolución de la agricultura en España: desarrollo capitalista y crisis de las formas de producción tradicionales. Estela, Barcelona.

Ortega VAlCÁRCEL, J. (1974): La transformación de un espacio rural. Las Montañas de Burgos. Estudio de Geografía Regional, Universidad de Valladolid.

Ortigosa, L. (1991): Las repoblaciones forestales en la Rioja. Resultados y efectos geomorfológicos, Geoforma, Logroño.

Rodríguez Martínez, F. (1977): La Serranía de Ronda. Estudio geográfico. Granada, Confederación Española de Cajas de Ahorro.

Ruiz Flavio, P. (1993): Procesos de erosión en campos abandonados del Pirineo, Geoforma, Logroño. 
Sánchez Aguilera, D. y García Coll, A. (2001): «Un siglo de cambios demográficos en el mundo rural» en Molinero, Majoral, R., García Bartolomé, J.M. y García Fernández, G., Atlas de la España rural, Ministerio de Agricultura, Pesca y Alimentación, pp. 86-105.

Sanz Herráiz, C. y Martínez de Pisón, E. (2015): «Paisajes de la Sierra de Guadarrama», en Mejías Moreno, M. El Parque de la Sierra de Guadarrama. Cumbres, paisaje y gente, Ministerio de Economía y Competitividad, Ministerio de Agricultura, Alimentación y Medio Ambiente, pp.304-358.

SEnAdo (2015), Informe de la Comisión especial de estudio sobre las medidas a desarrollar para evitar la despoblación de las zonas de montaña http://www.senado.es/legis 10/publicaciones/pdf/senado/bocg/BOCG_D_10_ 550_3678.pdf

SENAdo (2015), Comisión especial de estudio sobre las medidas a desarrollar para evitar la despoblación de las zonas de montaña: Publicaciones http://www.senado.es/legis 10/publicaciones/pdf/senado/ds/

Simpson, James: Spanish agriculture (1775-1965). The long siesta, Cambridge University Press, Cambridge, 1.

UE (2011): Agenda Territorial Europea 2020. Hacia una Europa integradora, inteligente y sostenible de regiones diversas. Aprobada en la reunión informal ministerial de los ministros responsables de ordenación del territorio el 19 de mayo de 2011 en Gödöllö (Hungría).

Valenzuela Rubio, M. (1977): Urbanización y crisis rural en la sierra de Madrid, Madrid, Instituto de Estudios de Administración Local. 